\title{
Architecture \& Practice: Pre-Modern Training for Post Modern Practice International Design Build: Educational \& Professional Experiments
}

\author{
PHILLIP GALLEGOS \& MARIA DELGADO \\ University of Colorado Denver
}

In order to bridge the radical gap between education and practice, the undergraduate program at the University of Colorado Denver has experimented with study abroad programs in the undergraduate curriculum to match architectural practice with education. The strategy has been to develop a curriculum in international design-build that can employ traditional studio skills of research, design and cultural criticism.

This paper explores the options and the outcomes of the strategic inclusion of international study and practice in the form of an undergraduate design/build course sequence.

\section{INTRODUCTION}

In a paper presented to an international design build conference in Halifax, a comparison was made between an educational design build program in Guatemala and a professional design global practice. This paper explores programmatic changes to an undergraduate design build study abroad program as a means for responding to criticism. It presents student data on expectations, collaboration, international context and pre-training strategies.

The Halifax paper compared the differences between educational programs and professional firms. Comparison issues included marketing, institutional support, team and individual personality requirements, and financial consequences, both business and institutional. This paper describes the corrections made to an undergraduate design build study abroad program. The newly designed program is in specific response to the previous professional comparisons and attempts to uncover transferable and teachable design skill sets.

The first design build course was to Guatemala. The revised study abroad program, and is the subject of this paper, is to Jalapa Nicaragua. The Nicaraguan program included a pre-trip class with training, comparisons and testing of basic premises about the practice of architecture and construction. The class was surveyed to determine student experiences, skills developed, expectations and pre-training effectiveness. Those premises included the traditional areas of academic inquiry such as research on political, economic, climatic, social context and materials-construction techniques. The implied agenda was to develop tools in the students to deal with uncertainty of design that can only be addressed in the field. The studio format, as an individual and archaic craft model, was invoked as a means of dealing with uncertainly of individual and collaborative processes.

The students were surveyed in the preparation class to determine acceptance of the academic and design intent given the uncertainty of accomplishing a construction project in an unfamiliar environment. After the study abroad experience, the students were surveyed again to measure achievement of skills, perceptions and expectations.

In the study abroad trip to Nicaragua, a working professional from the previously interviewed Denver office of $\mathrm{Oz}$ Architecture volunteered to participate in the preparation class as well as construction on site. An interview was conducted with her in order to include the context of the first paper's premise.

\section{CURRICULA CONTEXT: UNIVERSITY OF COLORADO DENVER PROGRAM}

The Design Build program officially began in 1991 and ultimately became a certificate program in the accredited Master of Architecture program. In 2011, a design build program was developed and delivered in the construction of a school in San Juan Comalapa Guatemala. The work continued in the winter of 2012 and became separated from the Graduate Certificate Design Build Program.

In the spring semester of 2013, a new Bachelor of Science in Architecture was approved for the College of Architecture and Planning. This new program had campus core requirements with a liberal arts focus that included a course in international perspectives. The initial generation of a study abroad proposal was to establish a 


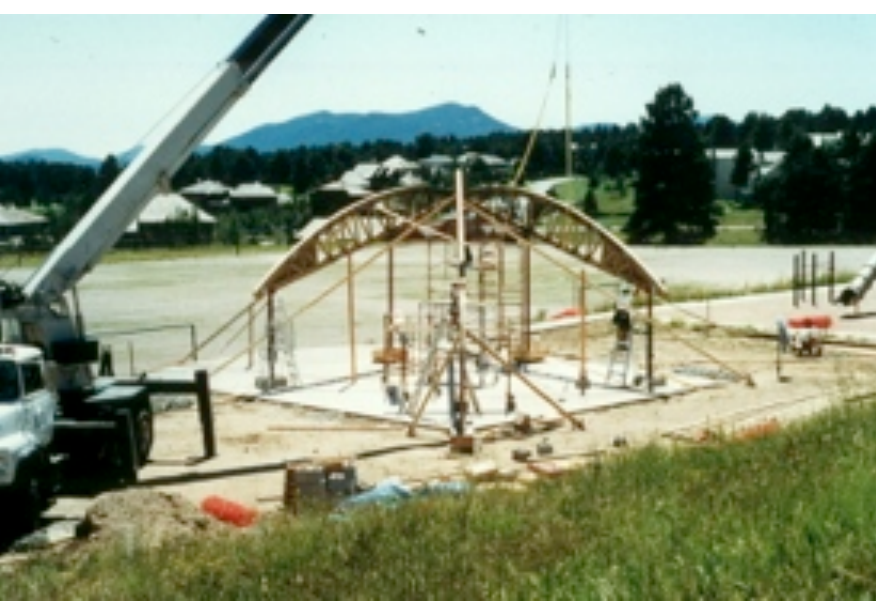

Figure 1

study abroad program to Nicaragua in order to provide a course for our new students with this focus. Field research on the possibilities for a study abroad program uncovered a wealth of opportunity in the northern mountains of Nicaragua to address significant environmental and political issues.

A proposal was advanced in the spring of 2014 and a two-course sequence was approved to begin in the fall of 2015 with a study abroad in the winter semester of January 2016. The first course was a seminar entitled "International Design Build." The second course approved was a winter study abroad program where participants of the first class would participate in the construction of a school in Jalapa.

\section{PROFESSIONAL CONTEXT: OZ ARCHITECTURE DENVER}

Following the first study abroad course of 2012 in Comolapa Guatemala, it was discovered that a major Denver architectural firm OZ Architecture had played a significant role in post-traumatic events in both Guatemala and Rwanda. This kind of international experience led to a discussion with a principal of the firm that led international projects, Steve Brooks.

In an attempt to create a graduate studio response to the stressed environment of Comalapa Guatemala, Mr. Brooks was interviewed on the issues of design in a stressed environment and the necessity of educational programs to transfer skill sets to an educational curricula. The result of this interview concerning studio means was a paper delivered to a previous International Conference held in Halifax Canada. The paper compared studio training and professional requirements for transferable skills.

The advent of the new BS Architecture program in 2013, however, provided an opportunity to re-define international design build as an undergraduate program that can address the vision of the core campus.

In the proposal for the Nicaraguan study abroad, OZ Architecture had several persons with experience in international projects for the firm. These young professionals expressed an interest in working in Central America. The value of the relationship with $\mathrm{OZ}$ Architecture was an embedded culture of international work in stressed environments that attracted young professionals. Thus, the concept of transferable design skills in an undergraduate education became a compelling connection with this firm.

A young professional from OZ Architecture named Michelle DeYoung became involved with the two courses as a reviewer of preparation design work and then an active participant in the construction work. Following the study aboard portion, she was interviewed to provide a parallel with the other professional in their office.

\section{COMPARISONS: CONSIDERED LESSONS}

The first interview with Mr. Brooks from OZ Architecture identified a number of individual skills that were important in employees eligible to be part of an international design team. There were essential skills identified to be eligible as a member of a design team working in a country with a traumatic history.

The professional insights he provided for essential skills included:

- An openness to unexpected learning

- An openness to unexpected teaching

- A willingness to help develop community capacity building in design

- An openness to interdisciplinary collaborations

- A willingness to foster community acceptance and perceptions

- The University of Colorado Guatemalan experience in its study abroad and studio activities identified outcomes that were expressed as:

- An understanding of a digital divide

- A understanding of analog construction versus digital fabrication

- A local distrust of the Central Government

The studio that was developed in 2013 was a graduate level final studio that sought to explore water pollution and means to design non-traditional systems as well as non-traditional materials and methods for re-generation of the natural water supply.

\section{RESEARCH QUESTION}

There were identified and intentioned lessons required of students to learn in international architectural programs that could be measured by surveys. In addition, there is the recognized pedagogy of the design studio that is largely understood in academia. In a professional practice with an international component, there are certain requirements to participate on design teams.

The central question became, what skills can be taught in an academic context that would be extremely useful to a design practice?

More specifically, upon initiation of the Nicaraguan study abroad proposal, the central question of this research activity became, "What 


\section{Pre-Departure Student Survey 21 Students}

\section{- Greatest Knowledge Gain:}

- Culture $\quad 100 \%$

- Design Approaches 100\%

- Materials $\quad 95 \%$

- Least Knowledge Gain:

- Language \& Behavior 30\%

- Economics $\quad 65 \%$

Figure 2: Survey

skills can be taught in an international architecture design build programs that are required in a professional international practice?"

\section{NICARAGUAN EXPERIMENT}

As we approached the proposal of a design build program in Nicaragua and a preparation class, there were certain assumptions that aligned with previous experiments. The assumptions included the need for analogue construction over digital fabrication; the problem of the digital divides between the two countries; and relationships with local of governing bodies in a traumatic environment. Layered over these first assumptions was the professional viewpoint of dealing with ambiguity of learning, teaching, capacity building and interdisciplinary collaborations. The first preparation course was intended to embed these ideas so that a field course in construction would be illustrated while implementing the work. Surveys were developed to attempt to test the learning experience after the preparation course and perceptions after the fieldwork course in construction.

Architecture 3807 International Design Build was the course developed for preparation of the trip to Jalapa Nicaragua. Given the requirements for international perspectives of the campus, the course included standard modules on history, culture, language norms, customs, political movements, economics and climate. In addition, a module was developed to discuss materials and to develop design approaches. This last module was a quasi-design studio meant to respond to the design problem of a school re-fabrication employing design teams.

\section{CURRICULA SURVEY}

In order to answer the research question of transferable skills, Maria Delgado, the research assistant and I developed a series of questions concerning perceived learning experiences at the end of the preparation class and at the end of the construction experience in Nicaragua.

In the first set of questions, we tested multiple areas of perceived knowledge gains the student felt was important to international and general requirements for learning abut other cultures. With multiple answers possible the students identified the greatest amount of knowledge gained in the preparation class as cultural context, alternative design approaches and alternative materials selection. The lowest knowledge gain they identified was in language $\&$ behavior, as well as economics.

Following the construction activity the students indicated that the first course prepared them most in cultural knowledge, alternative design approaches, and language skills. The lowest course preparation from the first class was in economics and history.

In response to questions more specifically focused on architectural training, we tried to assess the expectations of ambiguity in an unfamiliar context, as this was one of the underling intents of the course sequence.

A third of the students in pre travel and post travel felt the course fostered the principles of unfamiliar context, and therefore adaption. When we asked about international design-build, per se, we found that, while interest was very high prior to travel at $80 \%$. After the trip, only about two third increased their interest in international designbuild. That seems to be a significant drop as we fully expected a $100 \%$ increase in interest due to insights gained about adaptation to a new context.

The survey also attempted to see if the course could help students define, in their own mind, an appropriate definition, or role, of design generally, architecture, more specifically and international design build with its ambiguities. Students generally became more uncertain about what they defined as design before and after the second course in construction. The role of architecture in construction seemed to be close to being the same before and after the travel. However, design build in an international context made more sense in terms of definition of their role.

The role of international design build combined with the reduction of interest in international design build seems to imply that while students had greater clarity in their mind about design build during the preparation course, some had a reduced interest in its complexity from the field experience. The experience of design build in an international context seemed to help students find clarity on long term career path internationally with skills they could transfer, or reject global work as a career option.

Finally in the survey, in and attempt to strengthen our two courses, we asked the students the students to identify multiple strengths and modules to improve. The most surprising result was an equal number of students that felt the course was culturally strong and yet needed improvement in the module on local culture.

Another surprising result was a great interest in learning to develop design and construction teams prior to going on a design build trip and no comments about teambuilding after the trip. The professional observer on the trip portion indicated that she was amazed at how the students self-directed team activities and organization. Thus from her observation and our survey, it seemed that a course strength was in the dynamics of team building that became a part of the ingrained onsite ethics of the students 


\section{Student Observations}

\section{- Course Strengths}

- Pre: Learned Culture 6/19

- Pre: Team Building 4/19

$(32 \%)^{*}$

- Post: Learned Culture 5/15

- Course Improvements

- Pre: Learned Culture 6/19

- Post: Team Building 0/19

- Post: Local Communication 3/15

*12/19 Student Responded
Figure 3: Survey

\section{PROFESSIONAL PERSPECTIVES}

While the first professional from OZ Architecture expressed a need to develop a preference to learn, teach, understand ambiguity and employ design as a community process, the second professional saw slightly more specific qualities.

Michelle DeYoung, the young professional from OZ Architecture that traveled with the students, was more direct about the pedagogical and professional observations. From her observations, she felt that construction language had to be strengthened and a grater emphasis placed on differing, fluid site conditions. It seems that no matter the time spent on thinking about ambiguity on a site and unexpected cultural contexts, the reality of on site conditions had to be dealt with as a team and community-learning situation. This idea seems aligned with Steve Brooks' notion in general terms, that a person must be able to deal with complexity and ambiguity simultaneously in order to engage and direct design and construction.

Ms. DeYoung also commented that the class works in the field helped to insure individual commitments to the profession of design.

\section{PROFESSIONAL LESSONS COMPARISONS CONCLUSIONS}

Significant observations from the two professional observations concerning skills required in the profession include the importance of an openness to assist the self-development of a design team.

Another conclusion dealt with a willingness to discuss and offer solutions to changing design conditions and documents. This parallels the Steve Brooks conclusion of embedding a willingness to simultaneously be open to learning and teaching within a team and with a community. This is an important skill in delivering architectural services from a professional point of view.

In order to be effective in a professional context, the professionals concluded that a transferable skill from academia included an ability to deal with ambiguity, teaching and learning skills, sensing the line between design work and field work with personality traits that prefer openness and discussion. Also of importance should be a
Transferable Skill Sets: Pedagogical to Professional

- Advantage to Stepping back to Essentials

- Digital vs. Analog Appropriateness

- Complexity vs. Simplicity

- DB Open-mindedness: Differences

- Internal Teams Building:

- Communication

- Specialty Contributions

- Leadership Qualities: Team responses

- Learn \& Teach

- Community Approach \& Language

Figure 4: Survey Results

willingness to build community bridges and to open to communications of all types and styles.

\section{CURRICULA LESSONS COMPARISONS CONCLUSIONS}

Following the survey and the interviews, it is clear that the twocourse sequence will require corrections and improvements.

In the preparation course, the course should its reduce emphasis on economics as a module.

The course, however, should focus additional language skills on construction language.

A new module should be developed on design as a community building process.

Finally, we should increase and intensify modules on engaging with cultures as well as cultures within cultures.

While it can be argued that the fieldwork alone should accomplish this final goal, preparation and debriefing of effectiveness should emphasize before, during and after engagement with other cultures in students.

Fieldwork must establish a more defined set of pedagogical goals that engender management skills. Of importance are the skills of digital and analog information management. The course should also engender the preference for design as an opportunity instead of a fixed iconic fetish. The course should also engender the skills of detailing on the move, which will help to strengthen the concept of employing ambiguity without anxiety. In terms of culture, the lens of local construction traditions can become an important tool to understanding culture, not just language and dress. There should be a continuation and emphasis on team skills while in the field along with observation of team dynamics. Finally, related to tea dynamics, attention to communication skills both verbal and physical can become an important skill to transfer to a professional firm. 
TRANSFERABLE SKILL SETS: CONCLUSIONS

In the final analysis, if college is intended to be a place to learn skills and critical thinking strategies, then those that are required in either the market place should have similarities. The most significant conclusion for this researcher is the importance of combining cultural perspectives with the academic and field rigors. Design build in another culture seems to have the ability to engender a significant understanding of other cultures embedded in the process of learning design. This is of significant importance to firms that specialize in international work.

Those transferable skills that the survey and the interviewees identified can be summarized as:

- $\quad$ Provide a bias toward understanding the advantages of recognizing essentials of processes, materials, and communications

- Discern the appropriateness of digital and analogue methodologies

- To identify simplicity of means amidst complexity of methods

- Design Build in this context requires open-mindedness of differences in means and methods

- Importance of team building in communication, special contributions, leadership qualities community approaches, local language and an opens to simultaneously learn and teach

The results of the survey of the students, the interview of the professional and the acceptance of the community form a triad for continued investigations and discussions in a global practice. 